Guzman, G. and Ulloa, W. 2020. "BIM Application in the Operation and Maintenance Management of a Sports Infrastructure." In: Tommelein, I.D. and Daniel, E. (eds.). Proc. $28^{\text {th }}$ Annual Conference of the International Group for Lean Construction (IGLC28), Berkeley, California, USA, doi.org/10.24928/2020/0015, online at iglc.net.

\title{
BIM APPLICATION IN THE OPERATION AND MAINTENANCE MANAGEMENT OF A SPORTS INFRASTRUCTURE
}

\author{
Giankeving Guzman ${ }^{1}$ and Wilfredo Ulloa ${ }^{2}$
}

\begin{abstract}
Operation and Maintenance (O\&M) stage is the most expensive phase during the life cycle of a building. Currently, much of the information used in there is still paper-based and is delivered to the owner months after the facilities are in use. Therefore, it is necessary to study the interaction between Lean principles and Building Information Modeling(BIM) Functionalities in the building during O\&M phase to optimize resources. This paper proposes a BIM-FM workflow and compares it with traditional Facility Management in a Peruvian sports infrastructure. The case study was Aquatic Center for the XVIII Pan-American Games and VI Parapan-American Games Lima 2019. The sport infrastructure was designed and built under an Integrated Project Delivery (IPD) environment applying BIM methodology until the construction phase. The main difference found is that proposed BIM-FM workflow improves the efficiencies of the workforce for accessing to accuracy and complete information about Facility's components. Finally, the paper presents barriers in the BIM-FM implementation evidenced in the case study.
\end{abstract}

\section{KEYWORDS}

Facility Management, Building Information Modeling, Information flow, case study,sport infrastructure.

\section{INTRODUCTION}

Facility Management (FM) practice still faces the need for solutions to amend the problems faced with information management, as a result of that, it is important to define efficient tools that allow us to store, access, and update all information from the construction stage (Teicholz, 2013). Currently, much of the information used in FM is still paper-based (2D drawings, reports, manuals) and is delivered to the owner months after the facilities are in use (Bortolini et al., 2016). Generally, FM team require access to the location of Building components to perform inspection and maintenance work anywhere in the facility. However, it is difficult for FM technicians to refer the traditional 2D CAD-based information in the facility, that means wasted workforce time (Yu, 2011).

The advantages and contributions of applying BIM and Lean in the Design and Construction stages are well known, but there have been fewer studies on how BIM can

1 Research Assistant, Virtual Design and Construction Laboratory, Department of Civil Engineering, National University of Engineering, Perú, gguzmang@uni.pe, orcid.org/0000-0003-3008-7867

2 Head of Laboratory, Virtual Design and Construction Laboratory, Department of Civil Engineering, National University of Engineering, Perú, wulloa@uni.edu.pe, orcid.org/0000-0002-8773-9590 
be leveraged in the Operation and Maintenance (O\&M) stage of a facility (Oskouie, Gerber, Alves and Becerik-Gerber,2012).

In this sense, this study carries out an integrative review of the subject, firstly giving a background on FM and the interaction between Lean principles and BIM Functionalities developed in previous research. The following is the case study where it is described its context and the current state of the traditional facility management flow. This paper proposes a BIM-FM workflow to capture and represent facility management information based on BIM Functionalities and Lean principles that can support Facility Management. The latter section leads to a discussion on comparing the traditional FM and the proposed BIM-FM workflow. Finally, the paper presents the barriers and conclusions of the case study.

\section{LITERATURE REVIEW}

Facility Management was established to operate and manage the building upon delivery by the Design and Construction team, providing value to the client for several years after delivery (Bascoul, Tommelein, Tillmann and Muxen, 2018). Building Information Modeling(BIM) is an important factor in improving decision making for buildings throughout their life cycle to eliminates waste and rework in a collaborative flow. Oskouie et al. (2012) explored the interaction between Lean principles and BIM Functionalities related to Facility Management practices. The following Table 1 summarizes BIM functionalities that support Operation and Maintenance.

Table 1: Adaptation of Interaction Matrix of Lean Principles and BIM Functionalities (Table 1 in Oskouie et al. 2012)

\begin{tabular}{|c|c|c|c|c|c|c|}
\hline & 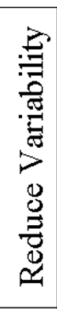 & 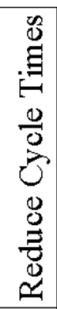 & 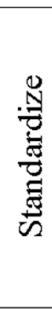 & 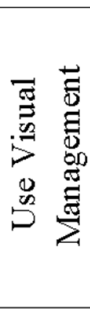 & 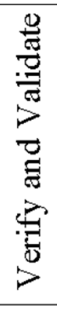 & 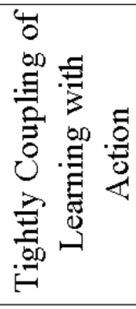 \\
\hline Generating As- Built Models & $\mathrm{x}$ & & & & & \\
\hline Controlling Lifecycle Cost Data & $\mathrm{x}$ & $\mathrm{x}$ & & & & \\
\hline $\begin{array}{l}\text { Controlling Lifecycle Environmental } \\
\text { Data }\end{array}$ & $x$ & $x$ & $x$ & & & \\
\hline $\begin{array}{l}\text { Effectively Locating Building } \\
\text { Comnonents }\end{array}$ & & $\mathrm{x}$ & & $\mathrm{x}$ & & \\
\hline $\begin{array}{l}\text { Facilitating Retrieval of RealTime } \\
\text { Integrated Building, Maintenance and } \\
\text { Management Data }\end{array}$ & $x$ & $\mathrm{x}$ & & $x$ & & \\
\hline Improving Maintainability Studies & $\mathrm{x}$ & & & & & \\
\hline Streamlining Space Management & $\mathrm{x}$ & & & $\mathrm{x}$ & $\mathrm{x}$ & \\
\hline $\begin{array}{l}\text { Enabling Personnel Training in Virtual } \\
\text { Reality }\end{array}$ & & & & $\mathrm{x}$ & & $x$ \\
\hline
\end{tabular}


Carbonari et al. (2015) developed a framework with two case studies where is confirmed graphic part should be minimal in BIM-FM Implementation for existing buildings and the main focus should be on the identification of the key data to create whole-life models.

There are automated toolkits to aid the development of as-built Building Information Model (BIM) (As-built model reflects on-site changes by the contractor to the original BIM) from inception to final construction (Parn, Edwards, and Draper 2016). Nevertheless, it is necessary to integrated this As-Built Information into existing Computerized Maintenance Management System(CMMS) systems to be utilised at during O\&M stages.

Construction Operation Building Information Exchange (COBie) is a standard format developed by the U.S. Army Corps of Engineers in 2007 that allows information collected during the design and construction process to be easily transferred to the operation and maintenance team (Teicholz, 2013). COBie data can be imported with different CMMS systems, from where infrastructure managers can easily access the equipment and its features. International data-standards like COBie (Construction Operations Building Information Exchange) which help to capture and record important data should be followed up at the beginning of projects. In order to identify relevant information for O\&M, facility managers should participate in an early phase of the project (Beck, Schmalz, Heyls and Binder 2016)

\section{RESEARCH METHOD}

A case study is conducted to explore the why's and how's of the contemporary phenomenon of integration in a new market in its real-world context (Yin, 2009). Peru and the rest of the Latin American countries are in the early stages of technology adoption and virtually all construction projects are learning by trial and error without following international standards. The case study method allows us to analyse and better understand why BIM Technology and Lean Principles are relevant not only in Delivery Phase (Design, Construction, and Commissioning) but also in Operational Phase.

The case is focused on an emblematic Peruvian Project for Games Lima 2019. While the main contractor delivers the project, the challenge is to integrate all the information generated in construction phase (drawings, equipment manuals, reports) to Facility Management team. Main obstacles to integration include: (1) Interoperability between BIM and CMMS Systems, (2) lack of BIM requirements to O\&M phase, (3) need for qualified staff in BIM tools (Ibrahim, Abanda, Vidalakis, Woods 2016; Teicholz 2013).

\section{CASE STUDY: AQUATIC CENTER}

\section{CONTEXT}

Aquatic Center is part of the National Sports Village (VIDENA), designed and built under a collaborative IPD environment for the XVIII Pan American Games and the Sixth Parapan American Games Lima 2019. With a total of 25'000 $\mathrm{m} 2$ of built area, it has a competition pool, a diving pool, and a warm-up pool. During Design and Construction, Integrated Concurrent Engineering (ICE) meetings were conducted with key stakeholders for solving Design issues. During the construction phase, the 4D models were used to track and control the project. The case study focuses on the Operation and Maintenance phase of the swimming pool and HVAC systems that are the most important systems for ensuring the proper functioning of the sports infrastructure. That is why the $172 \mathrm{HVAC}$ 
and 49 pool equipment were modelled at a LOD 500 level. For instance, there are Chillers, water pumps, boilers and a full treatment plant for cleaning pool water.

The maintenance period in Aquatic Center, as well as in the entire National Sports Village (VIDENA) began with the completion of the last construction milestone and will last until December 2019, after which the Peruvian government will assign a responsible organization for the legacy period. The organization structure is based on the main maintenance contractor located at the top. All activities and observations were coordinated with the client Lima 2019 through its Venue Manager, this organization structure was kept during the period of games and post-games varying only in the number of employees.

During the operation of the sports infrastructure, several types of incidents and system failures occurred, which were treated without any planning or standard procedures with the sole purpose of resolving the anomalies to what is known as corrective maintenance. In the case of the preventive maintenance, a traditional flow was identified where the Facility Manager coordinated with the administrator of the sports facilities to program the preventive maintenance, after being executed and approved, these activities were registered in reports paper-based. Finally, these documents were stored in physical or digital Storage. As a result of that, there was wasting time when Facility Management Team needed to know the maintenance activities' status or trying to find specific information in file boxes. The study diagnosed the current state with the following workflow.

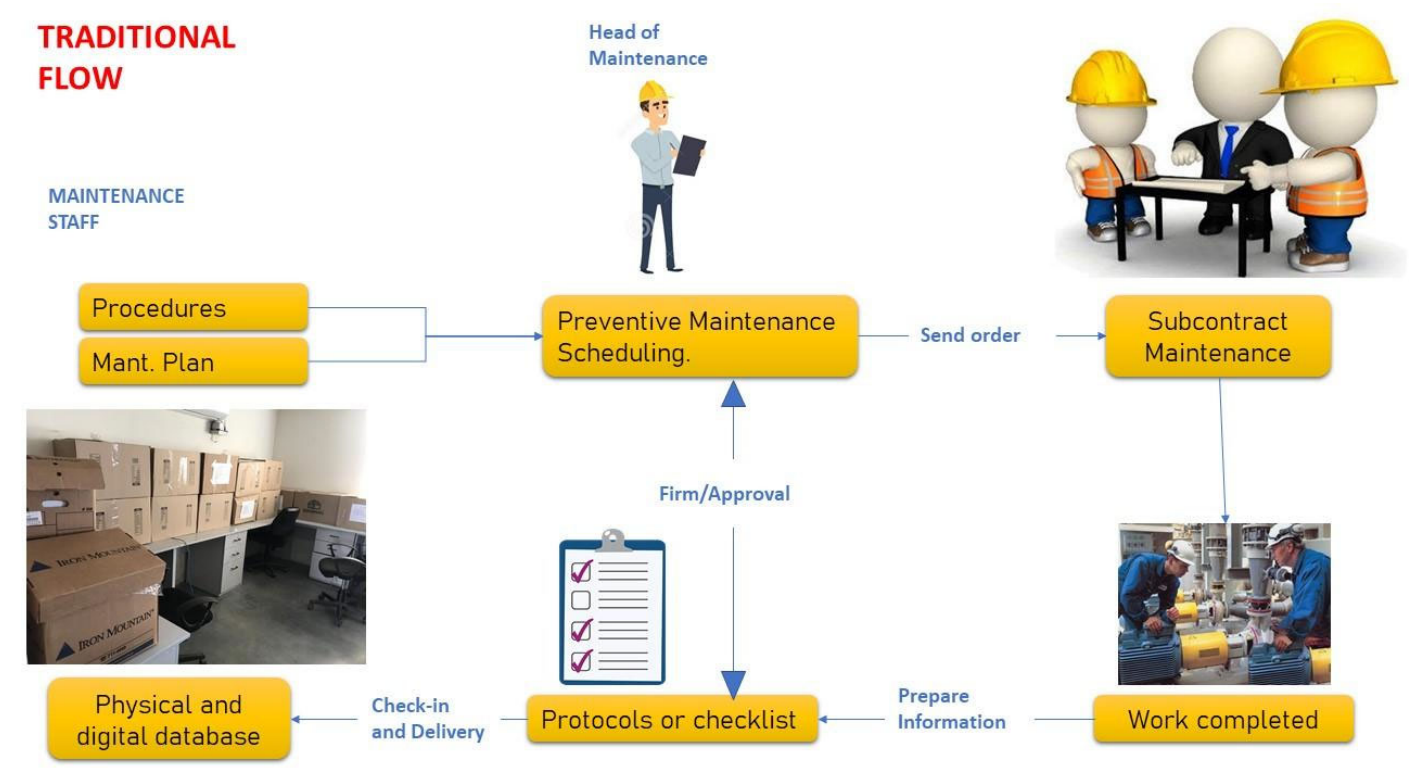

Figure 1: Traditional flow of maintenance activities

\section{BIM-FM WORKFLOW PROPOSAL}

Given the project scenario, it is necessary to change the approach and introduce methodologies and tools to respond to the problems associated with traditional maintenance flows. Using the Facility Management tool that integrates the information of the BIM models, the use of a Work Order (W.O.) system was proposed, as it is usually known in other industries. Work Orders help us to improve the effectiveness and 
productivity of maintenance, since it helps the FM team to obtain the necessary information and improve task tracking. The workflow was developed by following Lean principles and associating them with specific BIM Functionalities to keep a continuous flow to improve the FM team productivity.

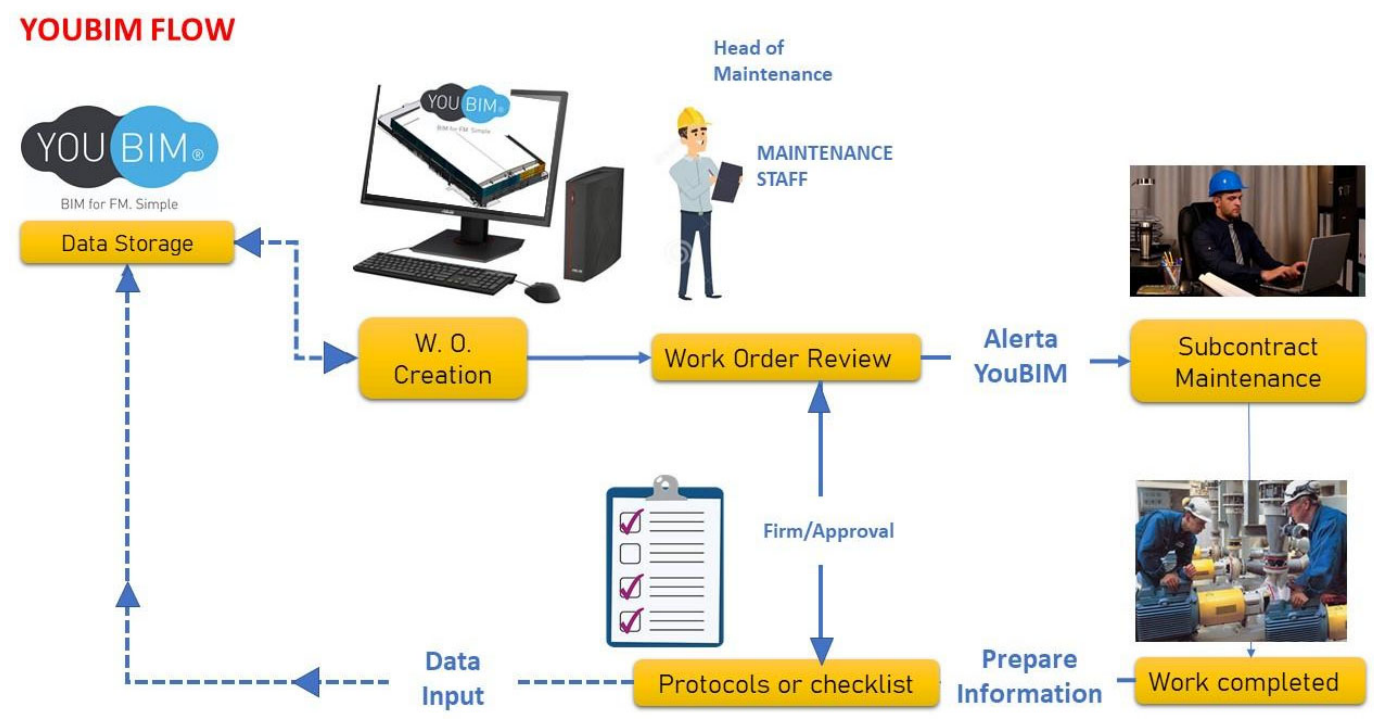

Figure 2: BIM-FM Workflow proposal

The BIM-FM platform is characterized by two essential inputs that are the COBie data and the BIM model. The first one contains all the information of the assets explained, the BIM model being parameterized is linked with that data and jointly loaded to the cloud in YouBIM. COBie has much of the information for maintenance so some minor updates are made within YouBIM, to add or remove some equipment from the model you must return to the native modelling software(Revit) and update it.

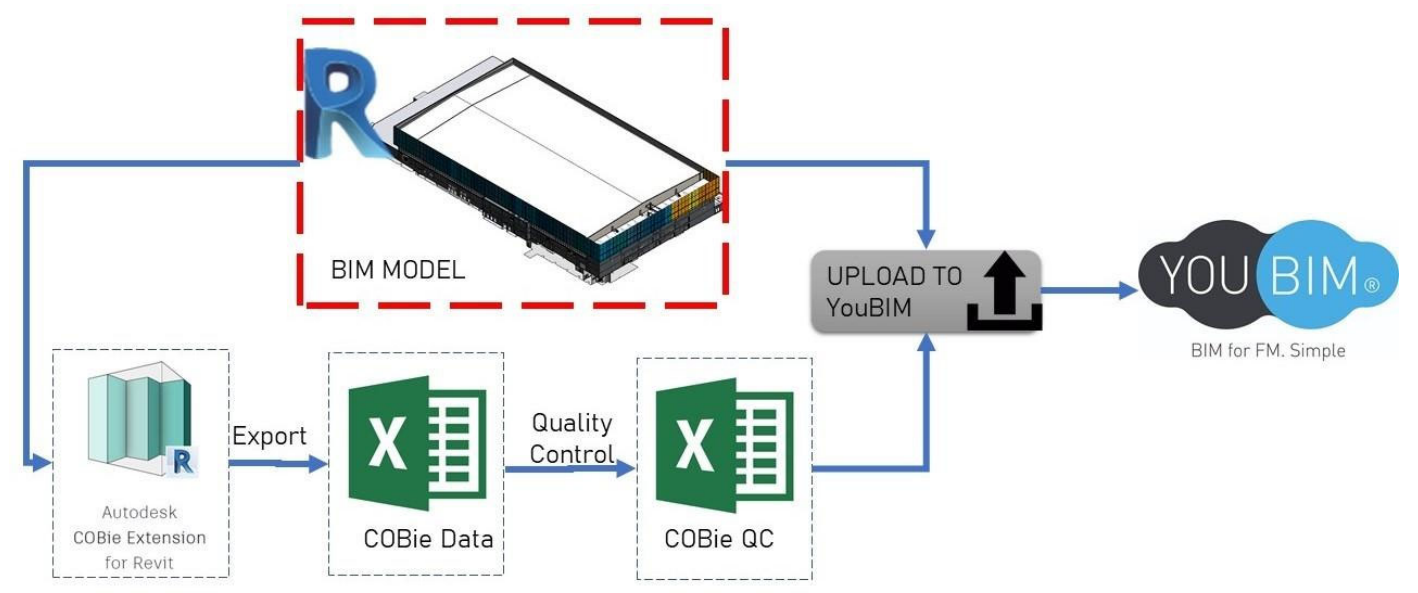

Figure 3: Exchange information workflow

The COBie format (Construction Operations Building Information Exchange) being an information exchange standard needs to follow a few steps to have reliable and correct data. In that sense, it shows the configuration of spaces or environments in a project and 
the identification of the assets in such a way that it contains both types of information. Initially, all this process is elaborated in Revit to later configure the output and export the database through COBie Extension for Revit which is BIM Interoperability. It is important to take into account that at the time of the automatic assignment of location to the equipment with the COBie extension, the rooms created must be above the false ceiling to cover that area where the equipment is installed. By default, the limit of the room is the False Ceiling and leaves the area between the structural slab and the False Ceiling empty.

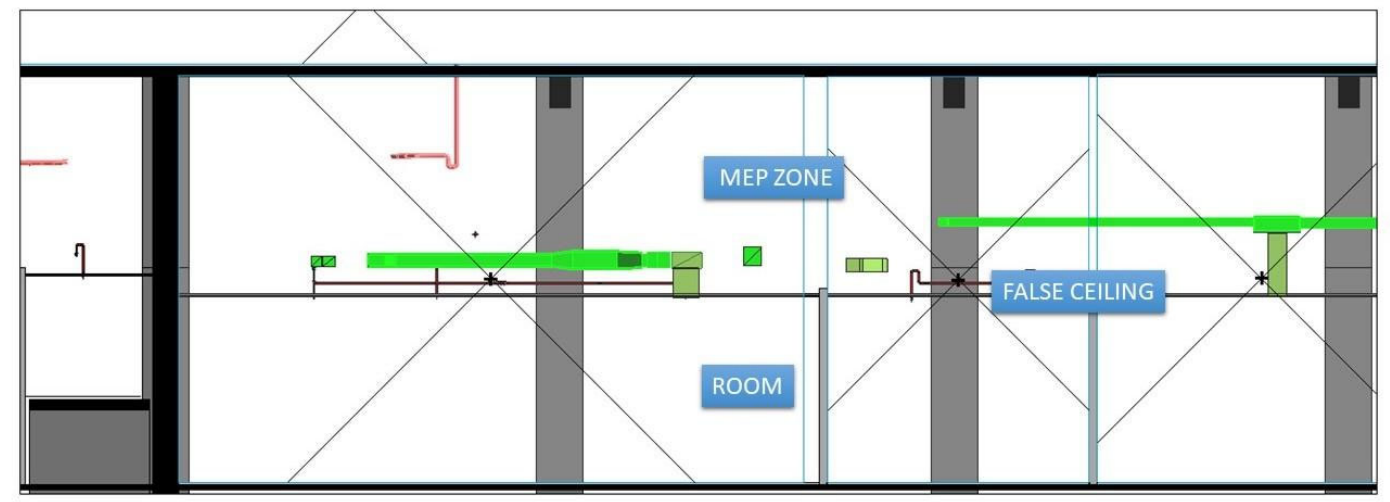

Figure 4: MEP zone above false ceiling level covered by Room

Below the bleachers or some differences in level between slabs it is common that the rooms do not cover the equipment, it was necessary to make a check to the rooms that were directly under the bleachers and ensure that the height of the room is high enough to cover the equipment.

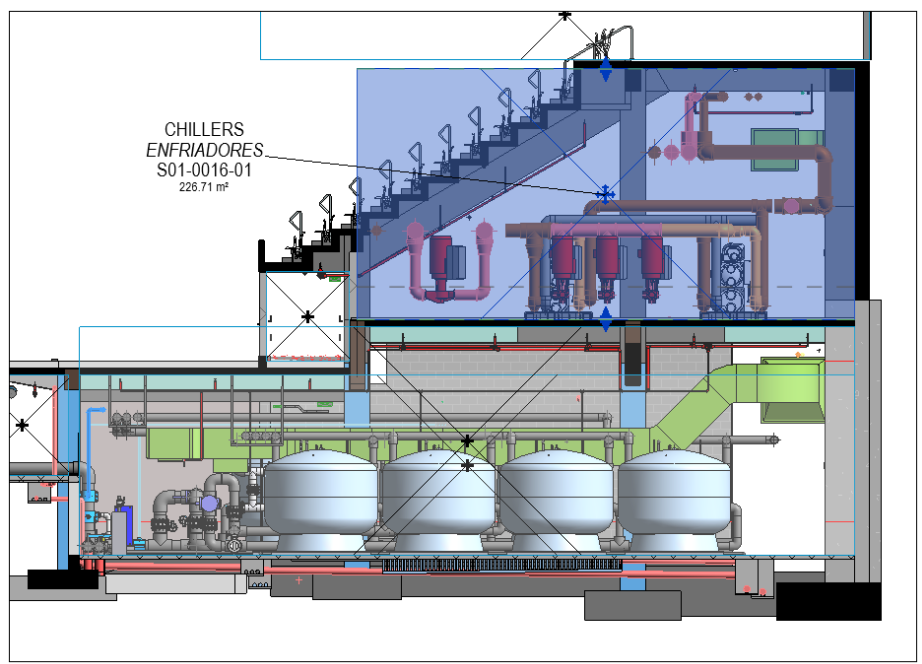

Figure 5: Chiller's room under the stairs

It is necessary to transfer all rooms from the Architecture model to the MEP models for automatic location assignment to the equipment. For this purpose, a visual programming was made in Dynamo to automate the process of transferring rooms. 


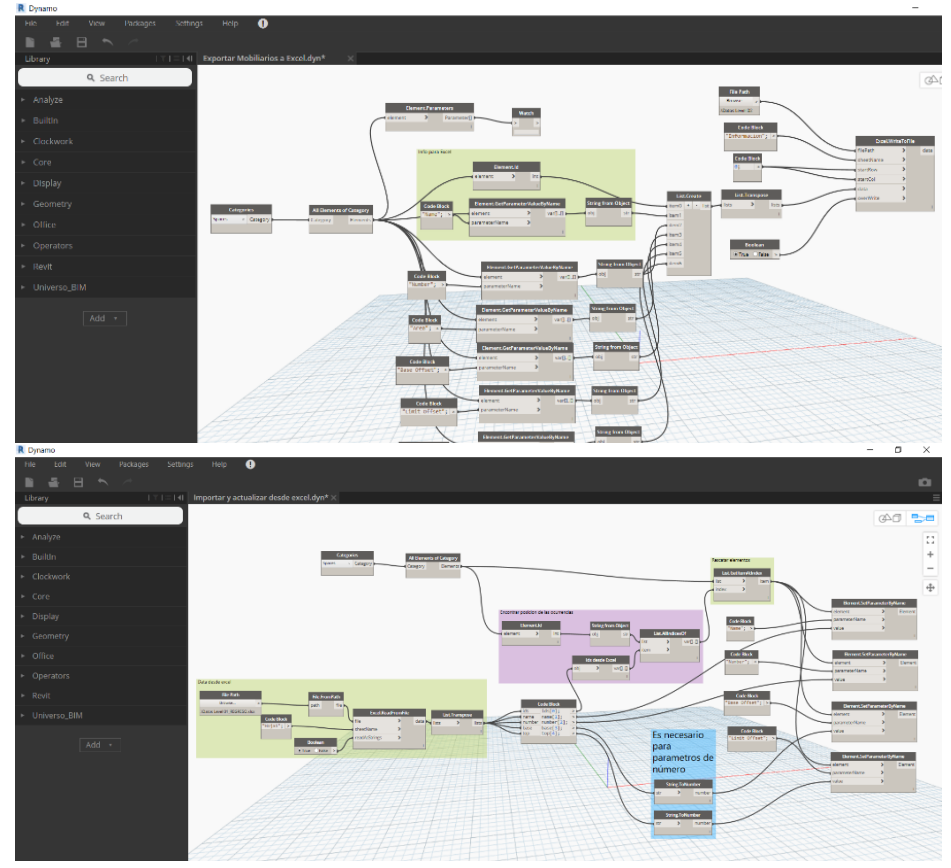

Figure 6: Dynamo Script to enter room name, number and height parameters to MEP models

The coding of the equipment is given by the tags with which they are represented in the design drawings, since until the time of installation of the equipment, its serial number, bar code or some other type of unique identifier is not yet known. These tags are loaded in the "Mark" parameter within the BIM model and then used as "Component Name" in the COBie format.

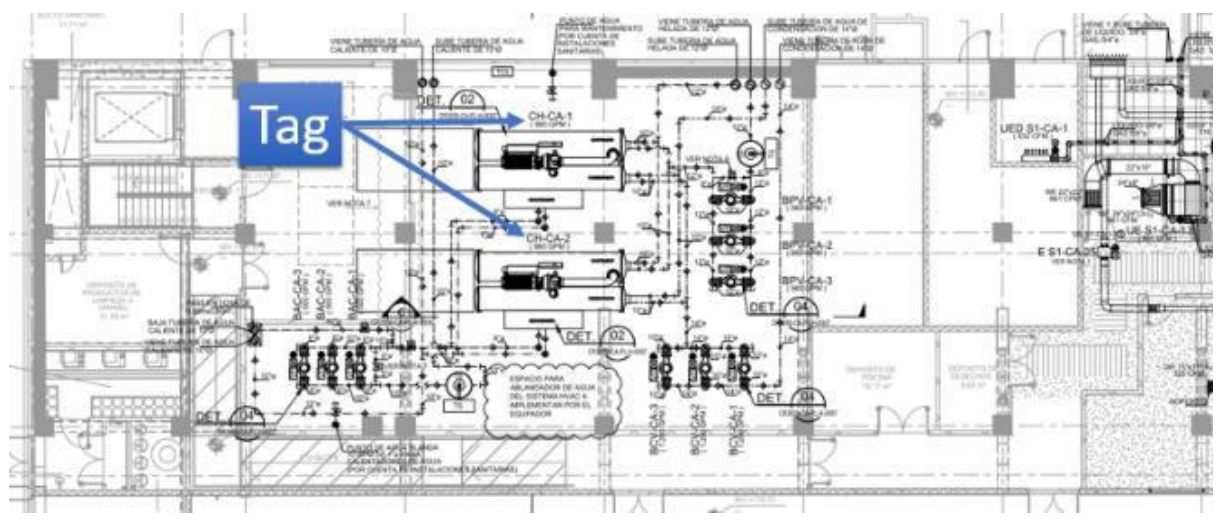

Figure 7: Design tag in the air conditioning plan of the Basement 01-Chiller's Room

Autodesk COBie Extension links the data in the BIM model to the standard COBie format. This means that the tool will transfer all the necessary information from the model elements to specific COBie parameters and then export the standard file as a deliverable. The COBie Extension has the following modules: Project Configuration, Contacts, Zones, Item Selection, Data Maintenance, and Format Creation. The final deliverable of the entire process is the COBie format Excel sheet that is exported from the Autodesk 
COBie Extension, this file is essential because it transmits the design and construction information to be used in Operation and Maintenance phase.

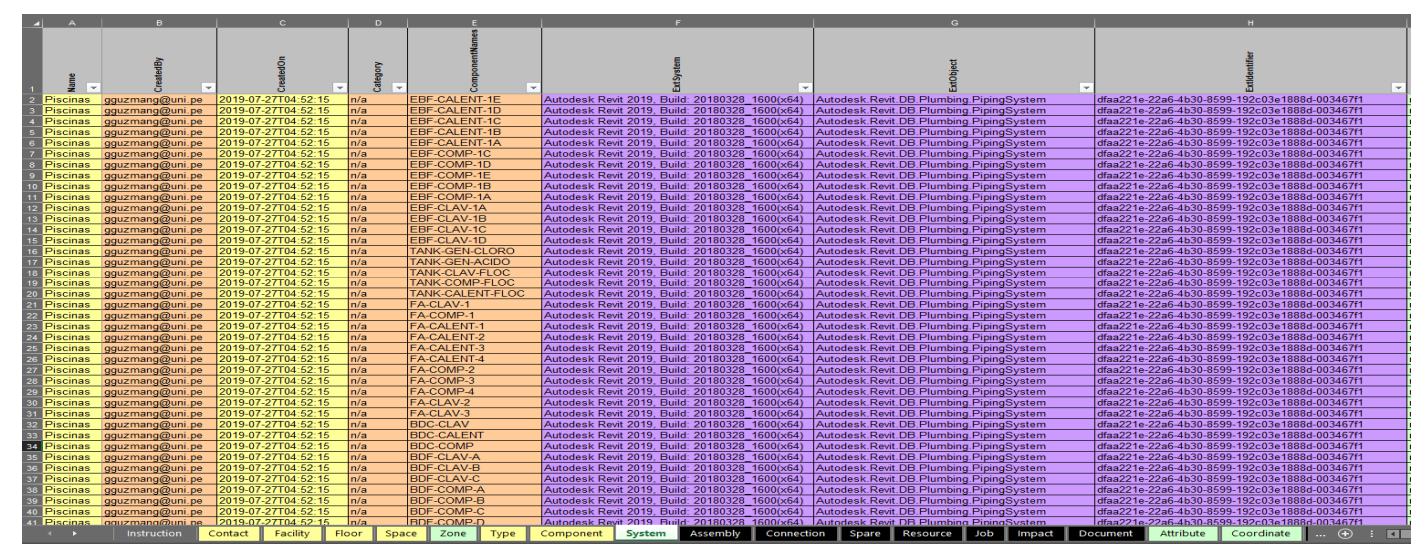

Figure 8: COBie file of Aquatic Center

With OpenSource COBie QC through programming it generates a report of all the errors that the analysed file contains. Meaningful errors in the Aquatic Center's COBie file are corrected as unique identification codes or needed data.

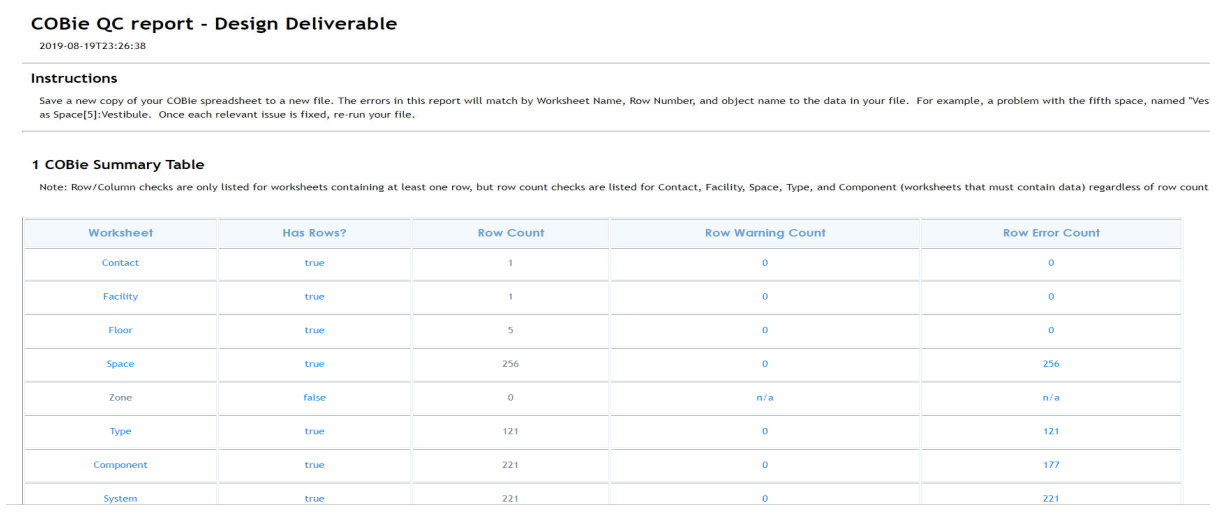

Figure 9: Detailed fault report of the examined COBie file

\section{BIM-FM FUNCTIONALITIES THAT SUPPORT THE PROPOSAL}

The paper identified three main BIM Functionalities which interact with Lean Principles adding value to Operation and Maintenance phase.

\section{EFFECTIVELY LOCATING BUILDING COMPONENTS}

A good practice carried out in the case study during the installation of the equipment was to label each piece of equipment with its respective identification Tag. These same tags were uploaded via COBie to YouBIM as the "Component Name" of the equipment. As a result, there is a unique communication language between the BIM-FM System and Onsite conditions. Incidents or failure reports are alerted by indicating the equipment Tag. On site FM team can navigate into BIM models to locate and verify specific equipment and its information from previous activities. It reduces cycle time of searching right an accurate FM information and promotes the collaboration in FM team because all of them are updating a unique system. 


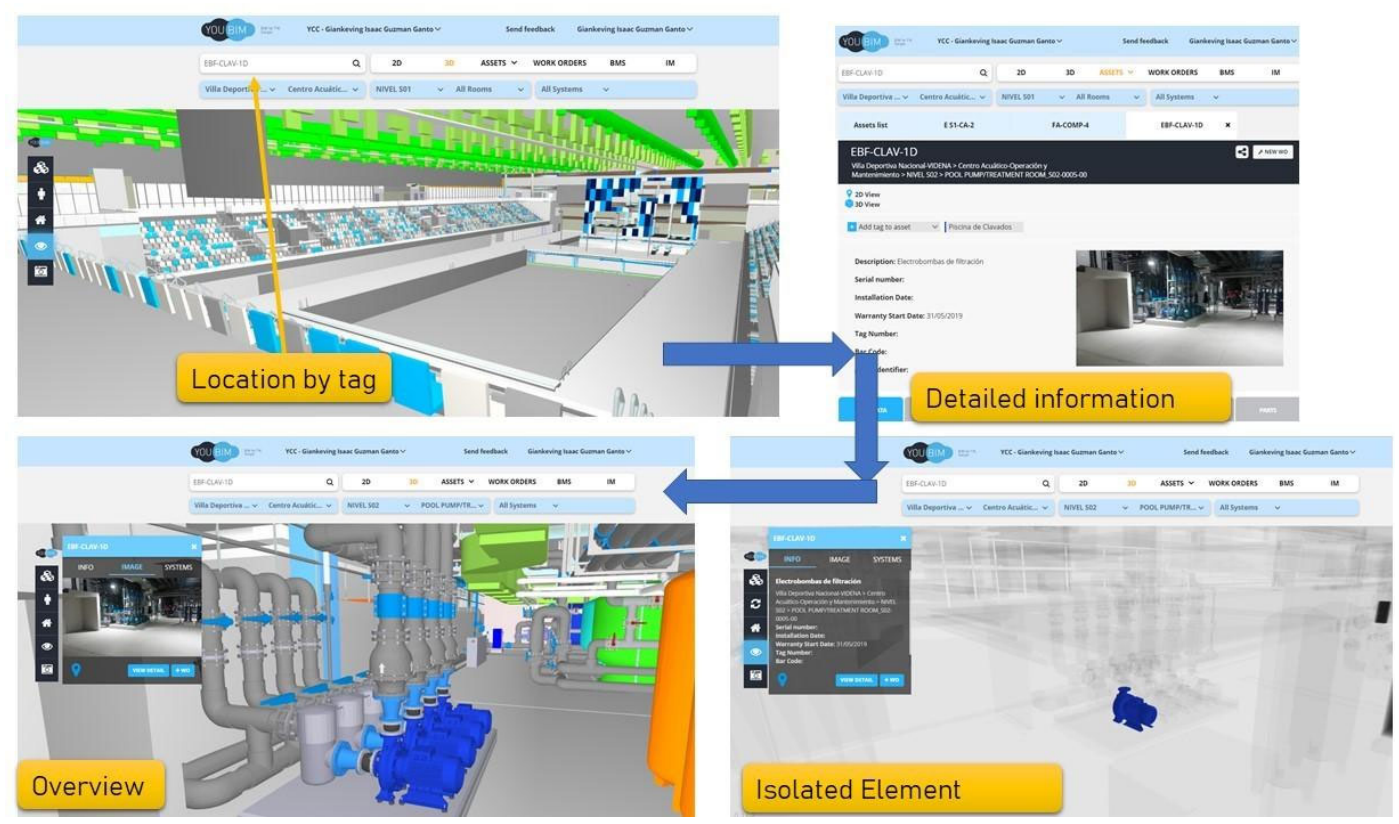

Figure 10: Equipment location on YouBIM using the tag

\section{Improving Maintainability Studies}

According to the BIM-FM workflow proposal, both preventive and corrective maintenance requires the generation of Work Order. Therefore, the maintenance planner will be able to analyse and make better decisions based on data. If an equipment has several Work Orders executed or to be executed, it is indicating that equipment is faulty and it would be convenient to replace this equipment verifying warranty conditions. Avoiding potential faults is relevant to reduce uncertainty in a normal operation.

According to the following breakdown of activities carried out traditionally and with the BIM-FM workflow proposal, a time of 20 minutes is saved for each incident, which is due to better access to information and the communication platform.

Table 2: Comparing task execution time with the traditional FM and the BIM-FM workflow proposal by each incident

\begin{tabular}{|l|c|c|}
\hline \multirow{2}{*}{\multicolumn{1}{c|}{ Activity Description }} & \multicolumn{2}{c|}{ Time(minutes) } \\
\cline { 2 - 3 } & Traditional & BIM-FM proposal \\
\hline E-Mail reception & 5 & 5 \\
\hline Instant messengers & 0 & 0 \\
\hline Understanding the Event & 10 & 5 \\
\hline Searching of Information & 10 & 5 \\
\hline Task performance & $\mathrm{T}$ & $\mathrm{T}$ \\
\hline Recording and data uploading & 20 & 10 \\
\hline Total & $45+\mathrm{T}$ & $25+\mathrm{T}$ \\
\hline \multicolumn{1}{|c|}{ Time saving per incident } & \multicolumn{2}{|c|}{$\mathbf{2 0}$ minutes (1/3 $\mathbf{~ h r )}$} \\
\hline
\end{tabular}

\section{Training for maintenance staff through Visual Management}

During the transition of the sports facilities to the final client, which is the Peruvian Institute of Sports, a series of training were conducted in order to explain the operation and maintenance process in the most important systems such as HVAC, Electrical 
Substations, swimming pools, among others. Thus, in the explanation of the scope of each system in the Aquatic Center, the trainer used visual support extracted from the BIM model to be shown on-site or in the training rooms. There was an active participation of the attendees because of the clear understanding of the systems.
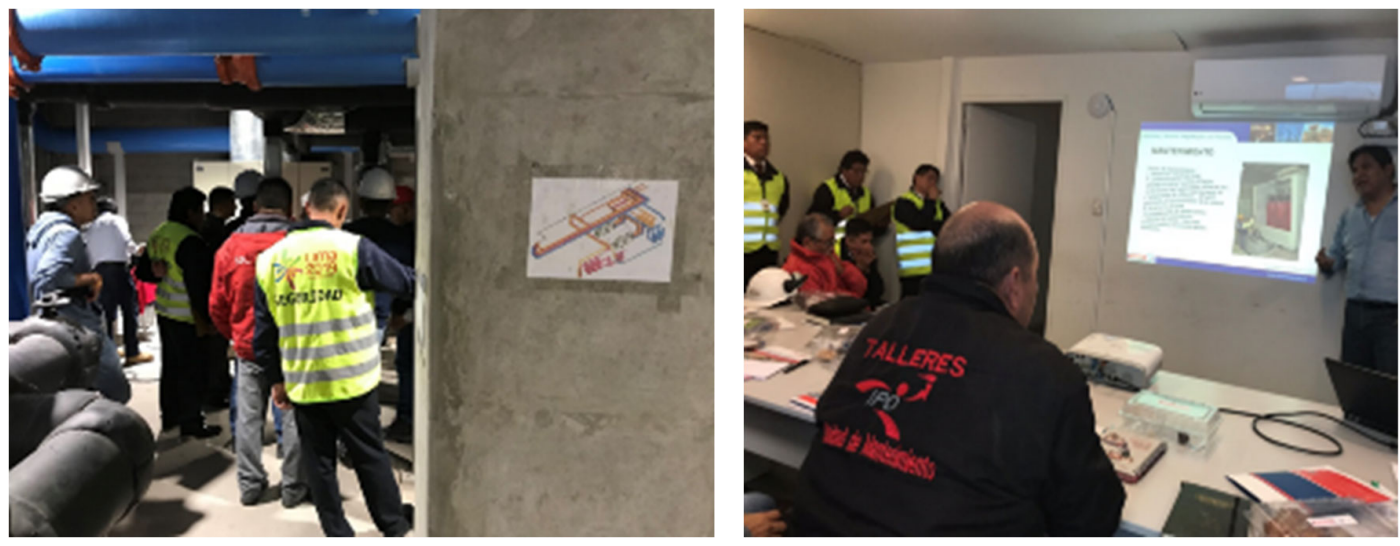

Figure 11: Facility Management training

\section{DISCUSSION AND ANALYSIS}

The authors discussed points such as accessibility for Facility Management Information. While in the traditional method, the FM technician needs to spend a lot of time searching paper reports on file boxes, with the information stored in the cloud this technician can access right information whatever on-site or in office. It is also interesting to explore how COBie Standard bridges the gap between Design-Construction and O\&M phases to an appropriate exchange information, this study uses the BIM-FM platform "YouBIM" but it is possible to link the same COBie Information with other FM tools. Activities planning aims to reduce the variability in Facility Management, the BIM-FM system can assist FM team to understand the schedule of task and send alerts to the person in charge of performing the task. This activities planning is known as preventive maintenance, this study suggests that future research can explore real-time monitoring as planning 's input.

In sum, the paper compares traditional maintenance flow with the proposed BIM-FM workflow, the following are main findings:

Table 3: Comparing traditional maintenance flow with the proposed BIM-FM workflow

\begin{tabular}{|c|c|c|}
\hline & Traditional Maintenance flow & BIM-FM workflow \\
\hline $\begin{array}{c}\text { Information } \\
\text { Storage }\end{array}$ & Stored in files boxes & Stored in the cloud \\
\hline $\begin{array}{l}\text { Information } \\
\text { Presenting }\end{array}$ & $\begin{array}{l}\text { Paper-based } \\
\text { 2D- Drawings }\end{array}$ & $\begin{array}{c}\text { 3D Model } \\
\text { COBie Standard }\end{array}$ \\
\hline $\begin{array}{l}\text { Information } \\
\text { Recording }\end{array}$ & Paper reports & Task tracking into BIM-FM System \\
\hline $\begin{array}{c}\text { Information } \\
\text { Searching }\end{array}$ & $\begin{array}{l}\text { Searching the information on paper } \\
\text { reports }\end{array}$ & $\begin{array}{l}\text { Searching by tag component into BIM-FM System } \\
\text { Navigation into BIM Model using filter tool } \\
\text { Linking to external related information files }\end{array}$ \\
\hline
\end{tabular}


While it is true that the results in this case study are evidence of the value that BIM adds to Facility Management, it is necessary to study other functionalities such as BIM integration with the Building Management System(BMS) and Space Management through simulators.

This research found some barriers in the process of case study, the details as follows:

- Lack of BIM Requirements to Operation and Maintenance phase: The general contractor's BIM requirements had not considered the use of BIM for Facility Management, the model delivered lacked the correct room definition, the equipment had no identification tag and was not configured to be able to export the COBie file. All this meant, performing modeling rework.

- Need for qualified staff in BIM tools: Even though all the information is generated in the BIM-FM system, when it is necessary to update the location of the equipment or modify an area, it will be necessary to edit it in the native modeling software, which in our case study is Revit. The Facility Management team had a conceptual knowledge of BIM but not technical skills to use BIM software.

- Lack of proof positive return of investment: When the proposal was presented to the FM team, there were no real benefits from other projects as a benchmark. This influenced the non-access to the full license of the BIM-FM platform and the acquisition of strong computers necessary for the revision of BIM models because all of them represented a high cost.

\section{CONCLUSIONS}

The BIM-FM workflow proposal is applied to a case study of a sports infrastructure for Games Lima 2019 to show its benefits and advantages over traditional Facility Management. The contrasting demonstrates the application of BIM tools in the O\&M phase improves the efficiency and productivity of the workforce in Facility Management tasks because they have access to an integrated information platform, whether it is required from the office or on-site instead of spending time looking for information in 2D Drawings, manuals, and other paper-based documents. The COBie standard enables the exchange of information between the Design \&Construction and Operation phase which is exported from a setting BIM model. This COBie files can interact with several FM systems for a better information management. The interaction between BIM Functionalities and Lean principles is relevant to support the proposal because the approach promotes collaboration in the whole life cycle of building exchanging complete and appropriate information along with stakeholders.

Due to revealed benefit using BIM in Facility Management, the study of other BIM functionalities such as real-time monitoring and Building Management System(BMS) is recommended for future study.

\section{REFERENCES}

Arencibia, J. 2007. "Fundamental concepts of building maintenance." Journal of Architecture and Engineering, vol. 1, num. 1, pp. 1-8.

Bascoul, A.M., Tommelein, I.D., Tillmann, P., and Muxen, S. (2018). "Towards Facility Management Participation in Design: A UCSF Case Study." In González, V.A. (ed.). Proc. 26 $6^{\text {th }}$ Annual Conference of the International. Group for Lean Construction, Chennai, India, pp. 505-515. 
Beck, S., Schmalz, S., Heyld, F., and Bilnder 2016. "Optimizing the value streamApplication of BIM in FM. Status quo in Germany." Proc. 24th Annual Conference of the International Group for Lean Construction. Boston, USA, pp. 93-102.

Bortolini, R. 2016. "BIM for the integration of Building Maintenance Management: A case study of a university campus." Proc. 11th European Conference on Product \& Process Modelling, Limassol, Cyprus.

Coello, G. 2015. "Development of a software for the maintenance management of large machinery for the Prefecture of Azuay." Salesian Polytechnical University.

East, W. 2007. "Construction Operations Building information exchange (COBie) Requirements Definition and Pilot Implementation Standard." US Army Corps of Engineers.

Ibrahim, K., Abanda, F., Vidalakis, C., and Woods, G. 2016. "BIM for FM: Input versus Output data" In: Proc. of the 33rd CIB W78 Conference, Brisbane, Australia.

Oskouie, P., Gerber, D. J., Alves, T., and Becerik-Gerber, B. 2012. "Extending the Interaction of Building Information modeling and lean construction." In: Tommelein, I. D. and Pasquire, C. L., Proc. 20th Annual Conference of the International Group for Lean Construction, San Diego, CA, USA.

Parn, E., Edwards, D. and Draper, R. 2016. "A Case Study of Building Information Modelling Enabled 'Information Totem' for Operations and Maintenance Integration" In: Proc. CIB World Building Congress, Tampere, Finland.

Tawfiq, S. 2018. "Developing an Interoperability Framework for Building Information Models and Facilities Management Systems." Creative Construction Conference, Ljubljana, Slovenia.

Teicholz, P. 2013. "BIM for Facility Managers.” John Wiley \& Sons, New Jersey.

Yin, R. K. 2009. Case Study Research: Design and Methods. Thousand Oaks, CA: Sage.

$\mathrm{Yu}$ Chiu, 2011. "Enhancing Maintenance Management using Building Information Modeling in Facilities Management" Proc. $28^{\text {th }}$ ISARC, Seoul, Korea, pp. 752-757. 